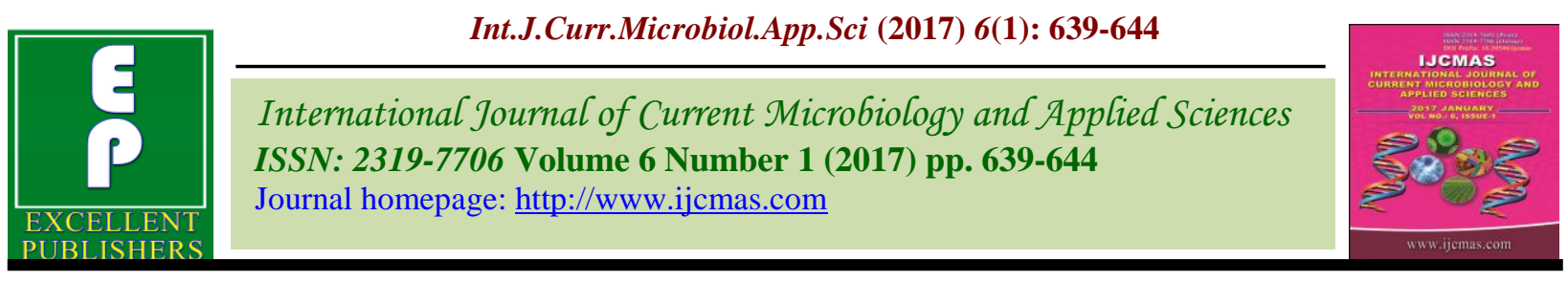

Case Study

http://dx.doi.org/10.20546/ijcmas.2017.601.077

\title{
The Study of Anatomical Variations of Axillary Artery - A Case Report
}

\author{
Mahesh Kumar*, Saim Hasan and Namita Mehrotra
}

Department of Anatomy, SHKM GMC Nalhar (Mewat), Haryana, India

*Corresponding author

\begin{tabular}{|c|c|}
\hline & A B S T R A C T \\
\hline Keywords & \multirow{4}{*}{$\begin{array}{l}\text { There are numerous variations in the pattern of Axillary artery reported by various } \\
\text { authors in previous studies; however, in this study more types of variations are found. } \\
\text { The axillary artery is a direct continuation of subclavian artery extendind from the } \\
\text { outer border of first rib to lower border of teres minor. Normally the pectoralis minor } \\
\text { divide the axillary artery into three parts. From first part, superior thoracic artery arise } \\
\text { and from second part thoraco-acromial and lateral thoracic, and from third part, } \\
\text { anterior circumflex humeral, posterior circumflex humeral and subscapular artery } \\
\text { arise, but in this case, a arterial trunk is arise from the third part of right axillary artery } \\
\text { and pass between lateral and medial root of medial nerve and divide in three branches. } \\
\text { i.e. Ant. circumflex humeral, Post circumflex humeral and Subscapular artery and this } \\
\text { trunk continue as profonda brachi artery along with radial nerve in radial groove. The } \\
\text { further course and the branching pattern of profonda brachi artery were normal. }\end{array}$} \\
\hline $\begin{array}{l}\text { Anatomical } \\
\text { Variations of } \\
\text { Axillary Artery, } \\
\text { subscapular } \\
\text { artery }\end{array}$ & \\
\hline Article Info & \\
\hline $\begin{array}{l}\text { Accepted: } \\
\text { 29 December } 2016 \\
\text { Available Online: } \\
\text { 10 January } 2017\end{array}$ & \\
\hline
\end{tabular}

\section{Introduction}

The variation in the branching pattern of auxillary artery is not uncommon (Sreenivasulu et al., 2015). The variation in the branching pattern observed considerably; the common known is the subscapular artery origination from a common trunk with the posterior circumflex humeral artery. The variations in the origin of anterior circumflex humeral and posterior circumflex humeral artery are occosional whereas anomalous origin is common for profonda brachii artey (Ramesh et al., 2008; Huelke, 1959). Axillary artery is the second next artery to be lacerated by violence and thus is more susceptible to diseases (Yoshinaga et al., 2006). Embryologically, axillary artery represents axial system of development together with brachial and anterior interosseous arteries (Senior, 1926). Sufficient knowledge of variant branching pattern of these vessels is important in the field of reparative surgery as well as during angioplasty procedures. The percentage incidence of presence of bilateral common subscapular-humeral trunk from 3rd part of axillary artery is $3.8 \%$ and bilateral thoracohumeral trunk is $1.9 \%$ (Saeed et al., 2002). Rare case of presence of bilateral double axillary artery was reported (Jurjus et al., 1999). In an alternative approach of femoral arterial cannulation, the right axillary artery is preferred in the presence of aortic or 
iliofemoral diseases (Kokotsakis et al., 2005). Since the axillary artery is in close relation with the cords of brachial plexus, during surgical repair of brachial plexus, it is important to have knowledge of such anomalous arterial trunk of axillary artery to prevent bleeding. Therefore, deep understanding of all possible variant branching patterns of axillary artery is useful to the cardio-vascular surgeons.

\section{Observations}

During dissection on a about 50 years old female, we noticed a variation in the branching pattern of right axillary artery. The branching patterns of its proximal two parts were normal. An arterial trunk was given off from its third part and it was passed between two roots of median nerve. The diameter of the arterial trunk was less as compared to the main artery.(fig-1). This arterial trunk gave three branches (ant. circumflex humeral, post circumflex humeral and subscapular artery) and continued as profonda brachii artery and enter in radial groove, along with radial nerve.
Further course of profonda brachii artery was normal.

\section{Results and Discussion}

The vascular variations in the upper limb are fairly common and reported extensively (Naveen et al., 2014). The origin of a common trunk from axillary artery and giving rise to common circumflex humeralsubscapular trunk and than continuing as profonda brachii artery was observed by George et al., which is in agreement with our case. but in our case the arterial trunk course through lateral and medial root of median nerve. The first report in literature about the origin of common trunk passing between two roots of median nerve was by Kogan and Lewinson in 1998.

Ramesh et al., (2008) also abserved a very similar case of common trunk like ours, including its course through the median nerve roots and giving branches of third part of axillary artery.

Fig.1 A arterial trunk arise from brachial artery and pass between two roots of median nerve

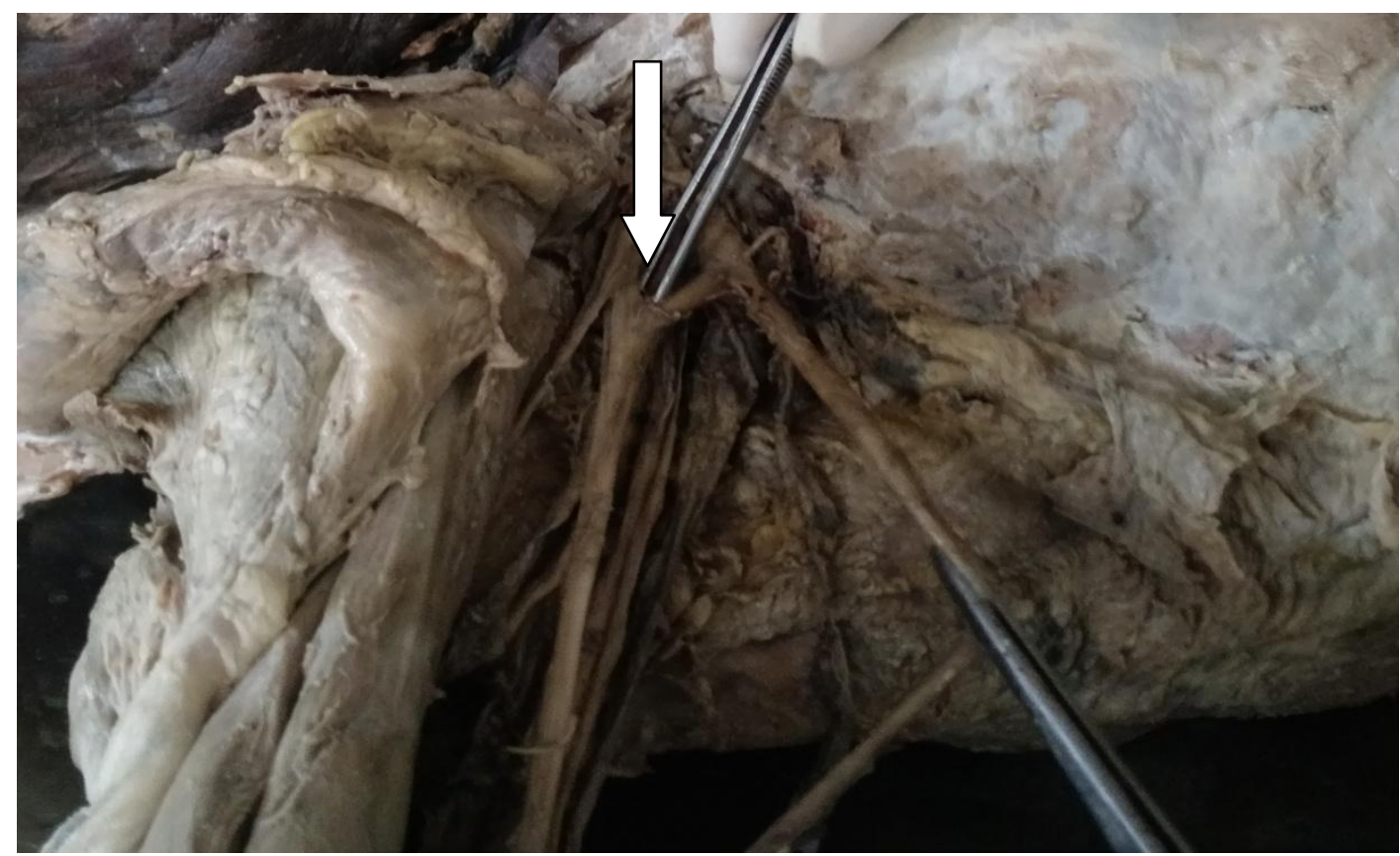




\section{Fig.2}

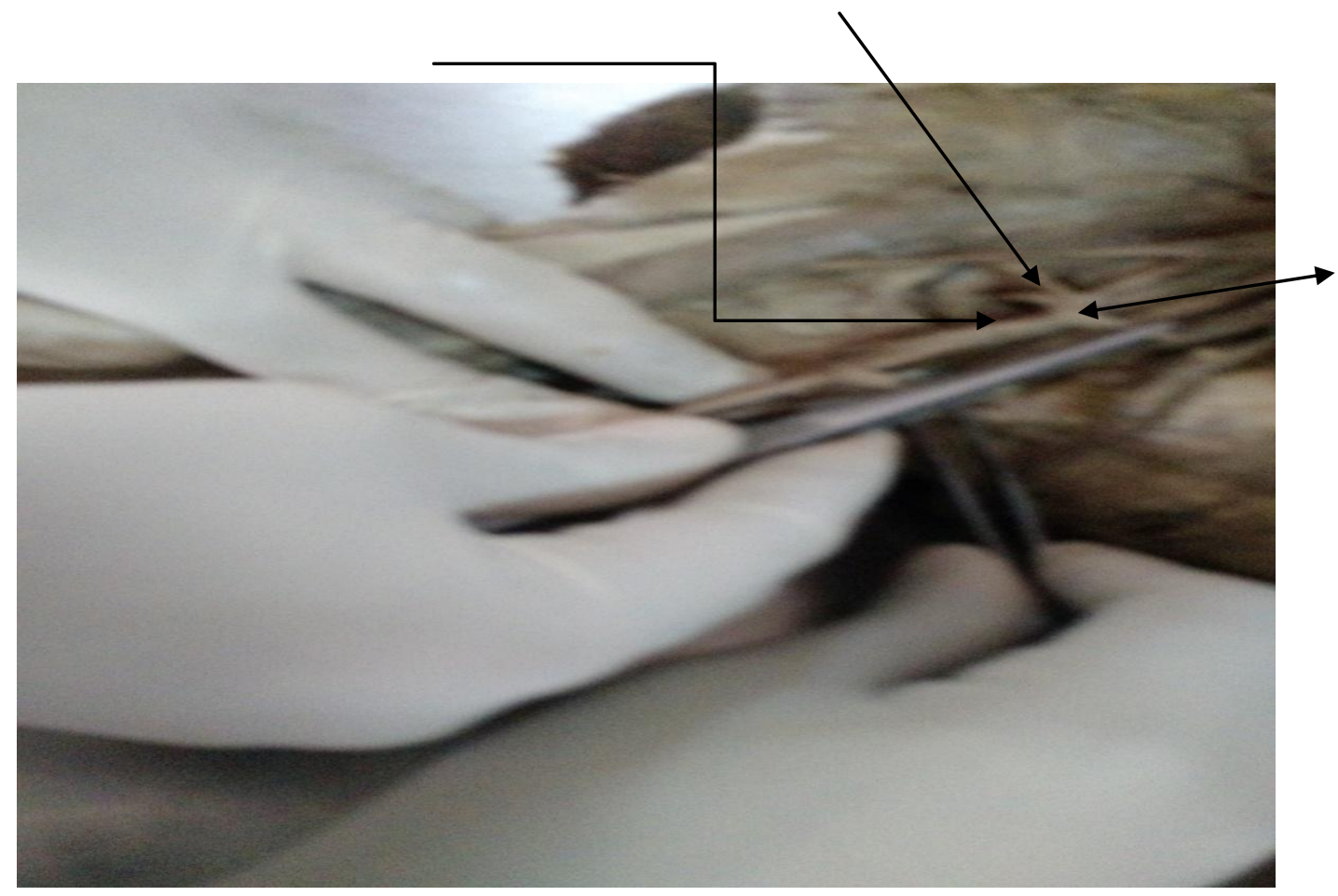

Fig.2 Three branches from arterial trunk-( ) Ant circumflex humeral, ( $\rightarrow$ ) Post circumflex humeral and $\leftrightarrow$ ) Subscapular artery

Fig.3 Ant. circumflex humeral artery

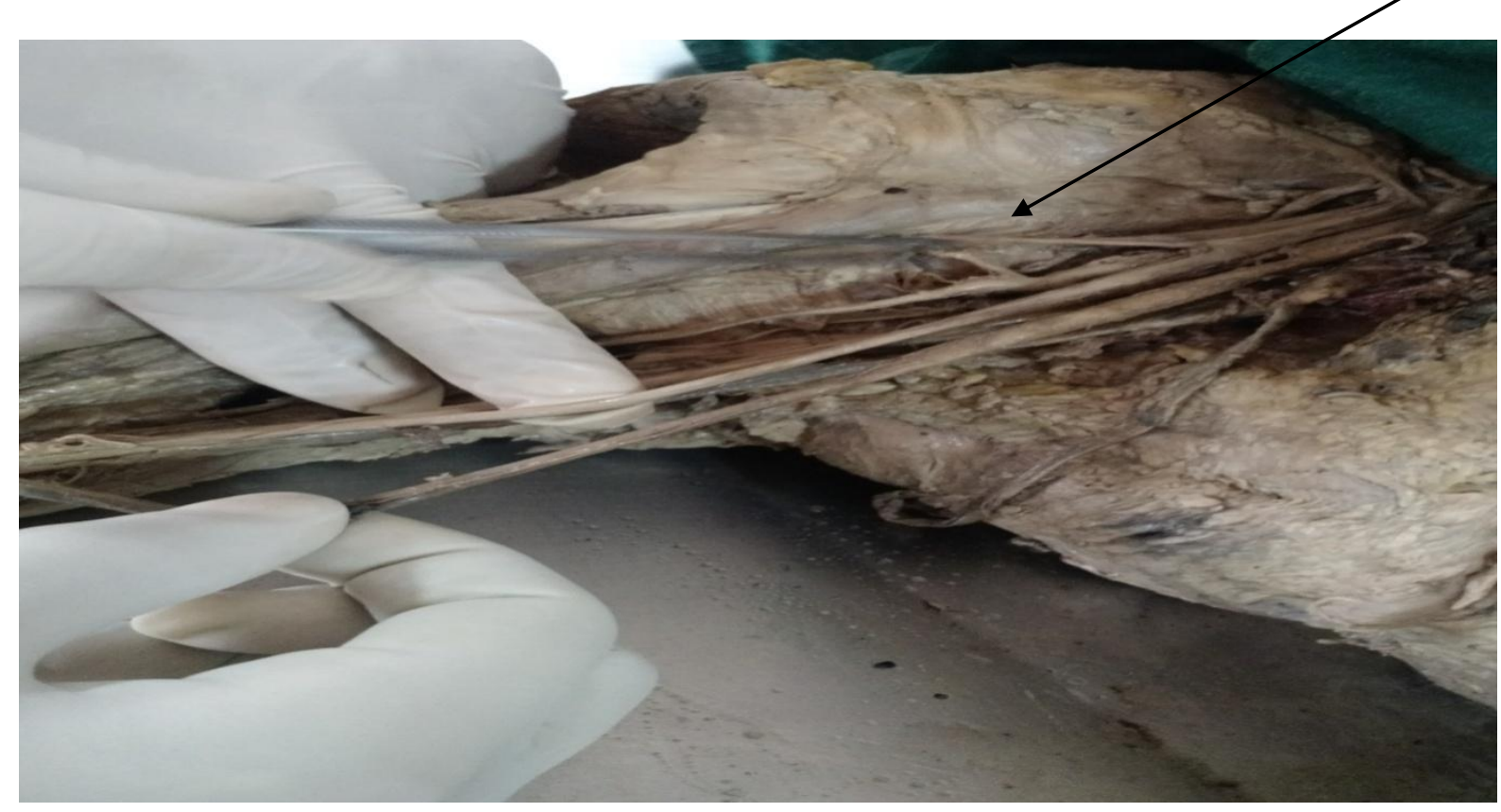


Int.J.Curr.Microbiol.App.Sci (2017) 6(1): 639-644

Fig.4 Post circumflex humar artery

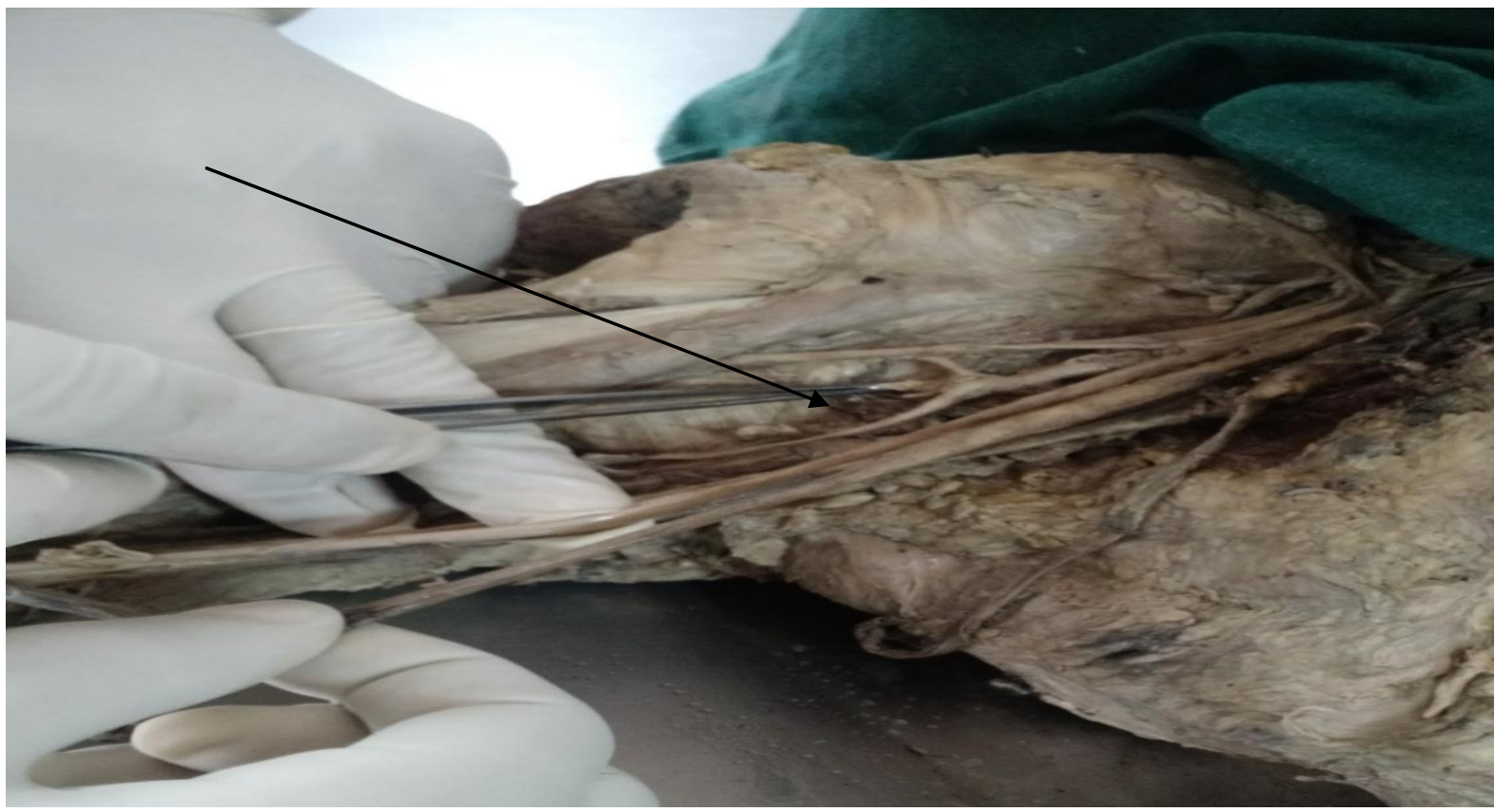

Fig.5 Subscapular artery

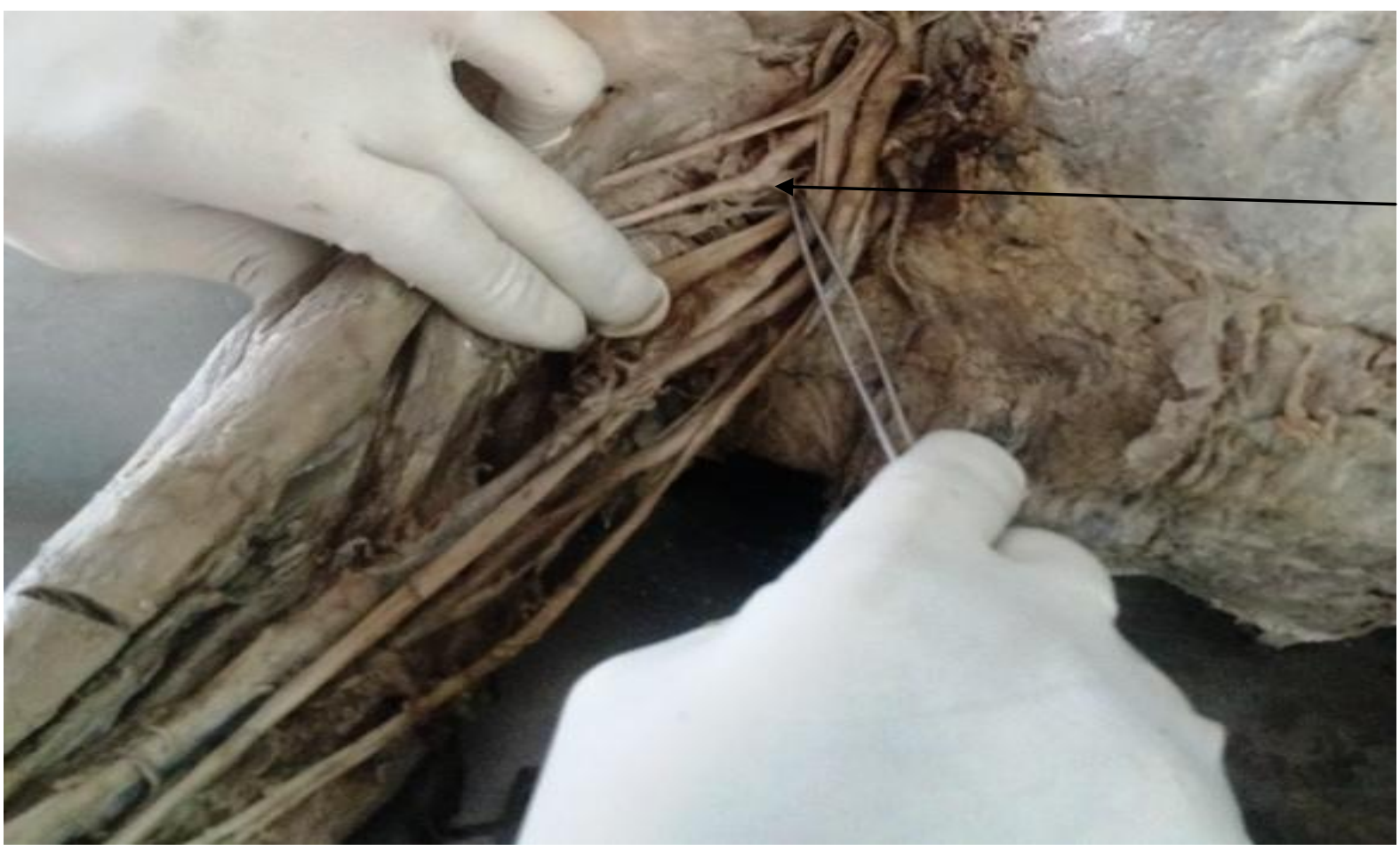




\section{Fig.6}

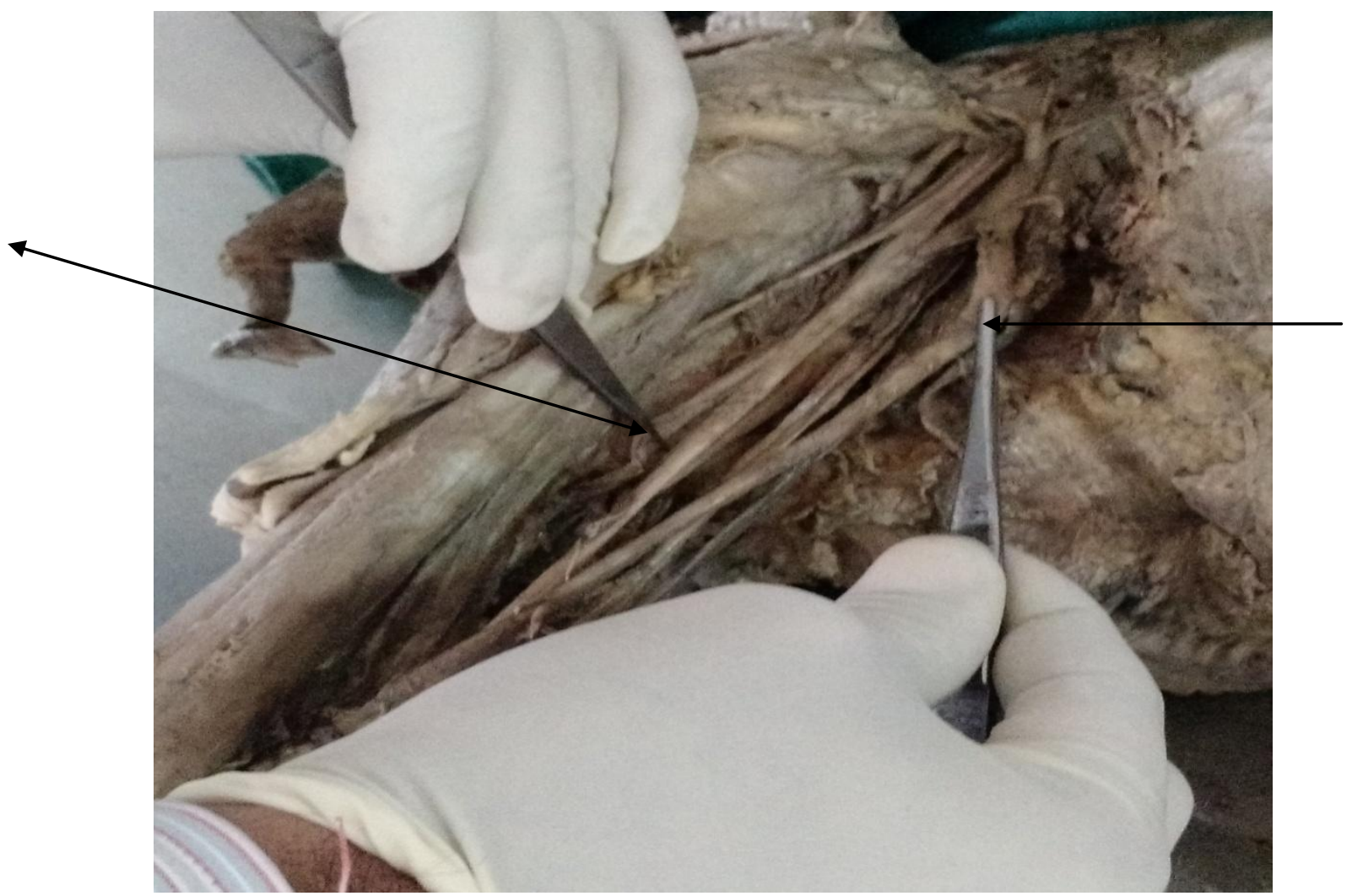

Fig.6 Brachial artery $(\longleftarrow)$ and profonda brachii artery (

In another case reported by Sawant et al., (2012), the axillary artery divided immediately into two division, superficial and deep. the superficial division continue as brachial artery and deep division gave all branches of axillary artery. But in our case main axillary artery gave branches from its first part and second part and branches of third part of axillary artery was given by the arterial trunk.

Naveen et al., (2014) also observed the same arterial trunk including its course through median nerve roots and giving branches of third part of axillary artery.

Bergman et al., observed that the third part of axillary artery is known to show its variant branching pattern. It includes, two circumflex humeral arteries arising from single trunk or together with profonda brachii or together with subscapular artery, which is in agreement with our case. Though a lot of variations was seen in previous studies by various researchers, but our study showed few additional one, which help in avoiding the possible diagnostic or interventional therapeutic errors.

\section{References}

George, B.M., Nayak, S., Kumar, P. 2007. Clinically significant neurovascular variations in the axilla and the arm. - a case report. Neuroanatomy, 6(1): 36-38.

Huelke, D.F. 1959. Variation in the origin of the branches of the axillary artery. Anat. Rec., 135: 33-41.

Jurjus, A.R., Correa-De-Aruaujo, R., Bohn, R.C. 1999. Bilateral double axillary 
artery: embryological basis and clinical implication. Clin. Anat., 12(2): 135-140.

Kogan, I., Lewinson, D. 1998. Variation in the branching of the axillary artery. A description of a rare case. Acta Anat., 162(4): 238-40.

Kokotsakis John, Lazopoulos George, Milonakis Michael. et al. 2005. Right axillary atery cannulation for surgical mamagement of the hostile ascending aorta. Tex. Heart Inst. J., 32(2): 189193.

Naveen, K., Patil, J., Satheesha, B.N., Mohandas Rao, K.G., Swamy, R.S., Deepthinath, R., Sheety, S.D. 2014. Variant origin of an arterial trunk from axillary artery continuing as profonda brachii artery-A unique arterial variation in the axilla and its clinical implications. Ethiop. J. Health Sci., 24(1): 93-96.

Ramesh Rao, T., Sheety, P., Suresh, R. 2008. Abnormal branching pattern of the axillary artery and its clinical significance. Int. J. Morphol., 26(2): 389-92.

Ramesh, T.R., Prakashchandra, S., Suresh, R. 2008. Abnormal branching pattern of the axillary artery and its clinical significance. Int. J. Morphol., 26: 38992.

Saeed, M., Rufai, A.A., Elsayed, S.E., Sdique, M.S. 2002. Variations in the subclavianaxillary arterial system. Saudi Med. J., 23(2): 206-212.[PubMed]

Sawant, S.P., Shaikh, More, R.M. 2012. Variant axillary artery- A case report. IJCRR, 4(21): 102-08.

Senior, H.D. 1926. A Note on the Developement of the radial artery. The Anatomical Record, 32: 220-221.

Singer, E. 1933. Embryological pattern persisting in the arteries of the arm. The Anatomical Record, 55: 403-409.

Sreenivasulu, et al. 2015. Frequency of variations in axillary artery branches and its surgical importance. Int. J. Sci. Study, 3(6): 1-4.

Turek Samuel. 1994. Turek's Orthopedic: Principle and their application. 5th Ed. Lippincott Williams \& Wilkins; p.708.

Yoshinaga, K., Kodama, K., Kameta, K., et al. 2006. A rare variation in the branching pattern of the axillary artery. Indian J. Plast. Surg., 39: 222-38.

\section{How to cite this article:}

Mahesh Kumar, Saim Hasan, Namita Mehrotra. 2017. The Study of Anatomical Variations of Axillary Artery - A Case Report. Int.J.Curr.Microbiol.App.Sci. 6(1): 639-644. doi: http://dx.doi.org/10.20546/ijcmas.2017.601.077 